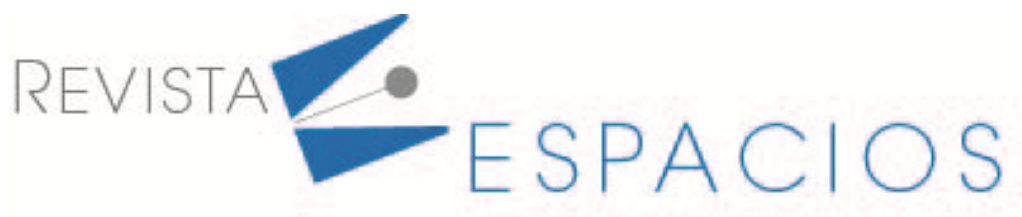

\title{
Integración productiva y desarrollo del turismo cultural
}

\section{Productive integration for the development of cultural tourism}

GUZMÁN, Beatriz E. ${ }^{1}$

PARRA, Ramiro ${ }^{2}$

TARAPUEZ, Edwin I. ${ }^{3}$

\section{Resumen}

La investigación busca proponer estrategias para la integración productiva entre los subsectores cultural y turístico del departamento del Quindío (Colombia) para el desarrollo del turismo cultural. La metodología es descriptiva y exploratoria y la población corresponde a gestores y expertos en el ámbito cultural y de alojamientos y restaurantes relacionados con el turismo. Se concluye que es necesario un cambio de concepción para impulsar como la innovación, incorporación de actores, formación del talento humano y uso de tecnologías de información y comunicación.

Palabras clave: cultura, integración productiva, turismo, turismo cultural

\begin{abstract}
This research seeks to propose strategies for productive integration between the cultural and tourist subsectors of Quindío province, Colombia,for the development of cultural tourism. The methodology is descriptive and exploratory and the population corresponds to managers and experts in the cultural field and to accommodation and restaurants in the tourism subsector. It is concluded that a change of conception is necessary to promote initiatives towards innovation, the incorporation of actors, the training of human talent and the use of information and communication technologies.
\end{abstract}

key words: tourism, culture, productive integration, cultural tourism

\section{Introducción}

A pesar de que la actividad turística en el Quindío (Colombia) surgió como alternativa para contrarrestar la crisis cafetera de los años ochenta, su evolución ha sido notable en los últimos años, convertiéndose en uno de los ejes estratégicos para el desarrollo del departamento. Por esta razón, han surgido esfuerzos de distintos actores para trabajar colectivamente y apostarle a los sectores más promisorios; es así como se inició un proceso de construcción de futuro en este sentido, y desde el 2004 el turismo se reconoce como una apuesta productiva dentro de la Agenda Interna de Productividad del Quindío, definiendo dentro de sus líneas el turismo cultural (Departamento Nacional de Planeación, 2007); así mismo, con la Declaratoria del Paisaje Cultural Cafetero otorgada por la UNESCO en el año 2011, se reafirma esta iniciativa, evidenciando el importante potencial que representa para el departamento.

Sin embargo, el turismo cultural no se reconoce aún como factor de desarrollo económico para el Quindío, lo cual se refleja en una oferta turística poco diferenciada que se enmarca en una supuesta valoración de lo rural y

\footnotetext{
${ }^{1}$ Docente. Administración de Negocios. Universidad del Quindío. Colombia. Email: beguzman@uniquindio.edu.co

${ }^{2}$ Docente. Administración de Negocios. Universidad del Quindío. Colombia. Email: rparra@uniquindio.edu.co

${ }^{3}$ Docente. Contaduría Pública. Universidad del Quindío. Colombia. Email: eitarapuez@uniquindio.edu.co
} 
cafetero, donde prevalece el interés económico y los elementos culturales que se incluyen no se corresponden en su totalidad con las expresiones y tradiciones autóctonas que han caracterizado por muchos años a la región. Adicionalmente, la pérdida paulatina de la identidad Quindiana y de las manifestaciones propias de la cultura cafetera (Guzmán, Parra y Tarapuez, 2019), son factores que se convierten en una amenaza tanto para los subsectores cultural y turístico del departamento. Así mismo, existen una serie de condiciones y factores económicos, socioculturales y políticos que han propiciado un alto nivel de fragmentación y desarticulación entre dichos subsectores, perdiendo de vista el enorme potencial que representa el turismo cultural para el departamento del Quindío.

Se hace necesario analizar la situación actual de ambos sectores, a partir de la identificación de las fortalezas y oportunidades de mejora, para iniciar procesos de construcción colectiva de futuro, mediante el aprovechamiento de las ventajas comparativas y la generación de ventajas competitivas orientadas a la articulación de los sectores y al desarrollo socio económico del departamento con un enfoque de sostenibilidad. Por consiguiente, el objetivo de este documento es proponer estrategias para la integración productiva entre los subsectores cultural y turístico del departamento para el desarrollo del turismo cultural.

Según Duis (2011), durante décadas ha existido una diferencia marcada entre los intereses del turismo y la conservación de los bienes patrimoniales de un territorio; sin embargo, en la actualidad, en el contexto del desarrollo económico y social, conciliar estos intereses mediante una interacción dinámica genera oportunidades y desafíos para ambos subsectores.

La planificación y desarrollo de los destinos turísticos parten de una "valorización turística del territorio" (Myttenaere y Rozo, 2010) y una "valorización cultural, social y turística de los recursos culturales y naturales" (Duis 2007); desde esta perspectiva, el turismo trasciende la dimensión económica y se reconoce como un sistema social, cultural y ambiental, que implica configuraciones y reconfiguraciones regionales. Por consiguiente, la naturaleza y el patrimonio cultural se convierten en herramientas para renovar los destinos de masas y potenciar el turismo en lugares en que "el clima y la geografía no ayudaron". Es a partir de ese momento que la cultura y naturaleza para muchos autores deben considerarse como un binomio cuando se habla de turismo, pues redefinen y reordenan el sistema. En este orden de ideas, la naturaleza pasa a considerarse parte del patrimonio nacional y es susceptible de ser protegida, conservada y gestionada (Campodónico, 2014).

Desde otro punto de vista, Guzmán y García (2010) denotan que la actividad turística tiene sus orígenes en la cultura, en particular su patrimonio, además el éxito de dicha actividad dependerá de cuánta importancia se les conceda a esos elementos para su rescate, conservación y difusión. Por ello, el turismo permite que el patrimonio sea un elemento que, puesto en valor, origine el interés de los visitantes gracias a la interacción que se establece entre el destino y el turista, pues este último viene a compartir y a vivir experiencias nuevas con gente de una cultura diferente a la suya. Por esto, el reto mayor del patrimonio es mantener la autenticidad, teniendo en cuenta que el visitante quiere creer en lo original y llevarse una impresión positiva cuando conoce un sitio turístico patrimonial, razón por la cual éste se convierte en un componente cada vez más valorado por él en las distintas ofertas de turismo y, en muchos destinos, juega un papel importante a la hora de elegir (Guzmán, 2013).

Por consiguiente, con la inscripción del Paisaje Cultural Cafetero de Colombia (PCCC) en la lista de Patrimonio Mundial por parte de la UNESCO en junio de 2011, se reconoce a 47 municipios de los departamentos de Caldas, Risaralda, Quindío y norte del Valle del Cauca, y al conjunto de atributos que representan las expresiones materiales de la cultura cafetera y denotan los valores excepcionales y universales del PCCC. Los 15 atributos fueron definidos por el Ministerio de Cultura de Colombia y reflejan las características propias de la región alrededor de la producción del café, las relaciones de sus habitantes y la herencia cultural (CONPES, 2014). Esta condición representa una invaluable oportunidad para el desarrollo del turismo cultural en el departamento del Quindío. 
El departamento del Quindío es el segundo de menor tamaño en Colombia, con una extensión de $1.845 \mathrm{~km}^{2}$ y su capital es la ciudad de Armenia. Está dividido en 12 municipios de los cuales 11 forman parte de la Declaratoria del PCCC (figura 1).

Figura 1

Ubicación del Quindío en Colombia y división administrativa en municipios

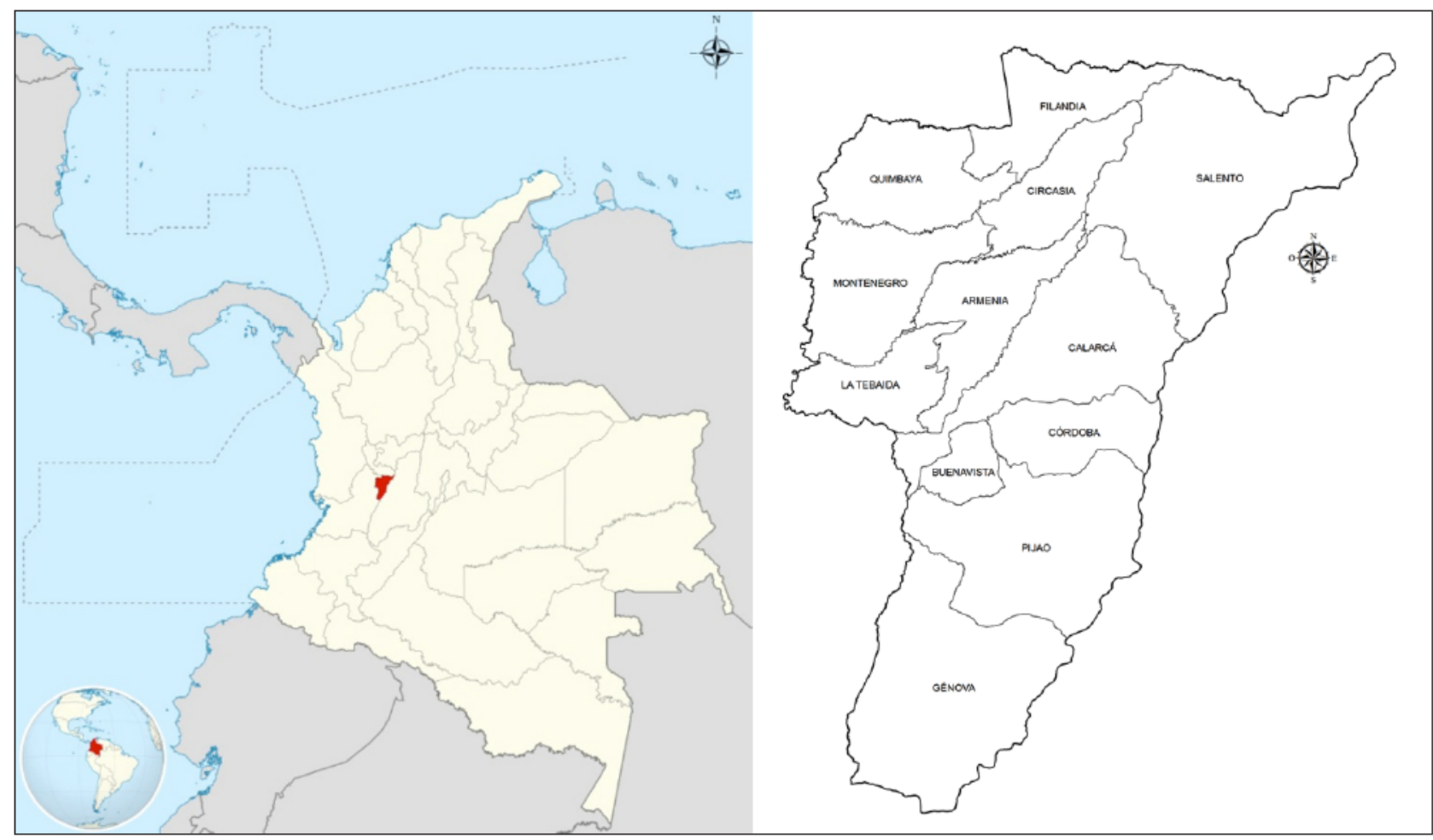

Fuente: Gobernación del Quindío y Departamento Administrativo Nacional de Estadística (DANE).

El turismo cultural como forma de consumo cultural y especialmente el turismo en sitios patrimoniales ha generado empleo, ingresos y bienestar en muchas partes del mundo, particularmente en las comunidades locales. En este escenario, el turismo está llamado a ser un proceso social que crea espacios de interacción entre visitantes, actores culturales y comunidades receptoras. Desde esta perspectiva, el turismo cultural se reconoce como una herramienta de gestión cultural y transformación social, porque busca consolidar los lazos entre las comunidades y garantizar la permanencia de los valores, la identidad y las tradiciones y, además, generar un beneficio económico (Ministerio de cultura, 2007).

La interacción dinámica entre turismo y cultura evidencia la importancia que representa la salvaguarda y valoración de atractivos de la zona como parte del territorio patrimonial y como medio para el desarrollo turístico. Según Anato, Rivas y González (2010), la oferta turística además de atributos o atractivos del paisaje natural, debe reflejar aquellos que identifican culturalmente a la población como su historia, gastronomía y artesanías; por consiguiente, la relación entre los actores culturales y el turismo posibilita la integración de las poblaciones, su cultura y patrimonio (Duis, 2011).

El desarrollo económico local, por su parte, se reconoce como un proceso dinamizador que debe ser liderado por actores locales para la definición y construcción de agendas locales. Según García (2004), estos procesos exigen cada vez más la participación activa de todos los agentes socioeconómicos involucrados directa o indirectamente, para facilitar innovaciones organizativas y tecnológicas en los sistemas productivos locales, los cuales deben estar respaldados por políticas públicas directamente relacionadas con los problemas económicos, 
sociales y ambientales, que faciliten la toma de decisiones estratégicas de acuerdo con las características particulares de cada región (Troitiño, 2002). Según García y Vargas (2016); estas políticas deben ser claras y estar articuladas con el sector privado y con las comunidades. Ahora bien, el desarrollo del subsector turístico surge de la información generada por las personas y se convierte en un activo estratégico para la generación de valor (Corona, Zárraga y Ruiz, 2015).

De otra parte, la competitividad analizada desde un enfoque de desarrollo local, reconoce la importancia de generación de clústeres para la integración productiva. Al respecto, Porter (1998) define un clúster como "la aglomeración de empresas e instituciones, que en un espacio determinado se relacionan con base en la producción de bienes y servicios", donde la principal intención son los beneficios derivados de la voluntad de cooperación, cuyo foco estratégico es el fortalecimiento de una industria o sector. En este sentido, los elementos intangibles son importantes para la implementación exitosa de acciones de fomento, tales como la existencia de una cultura local favorable al trabajo asociativo, la confianza de los actores y el sentido de pertenencia a la comunidad local (Gálvez, 2005, citado por Varisco, 2007).

Según Aldamiz, Aguirre y Aparicio (2014) el clúster aporta una red de conocimiento tácito para los actores pertenecientes al subsector turístico, caracterizado por un alto grado de cooperación, amistad y confianza entre las partes que la conforman. De otro lado, como respuesta a los retos de una nueva economía y como estrategia de desarrollo local, surgen los clústeres culturales, los cuales se convierten en un fenómeno que propicia un cambio en la relación entre el ámbito cultural y urbano, y evidencia la importancia que adquieren las interacciones sociales (Mommaas, 2004; Lorenzen y Frederiksen, 2007; Kadsson, 2010, citado por Rius y Zarlenga, 2014).

Ahora bien, según Sanabria (2010), la consolidación de estructuras turístico culturales es compleja porque "desborda el ámbito económico al comprometer las prácticas sobre protección del patrimonio y las intrincadas relaciones que en consecuencia se tejen para la gestión turística" (p. 129), y a pesar de que se han logrado consensos, aún se evidencia desarticulación entre los actores involucrados, razón por la cual representa un desafío integrar ambos sectores (Conforti, 2014).

Según el Ministerio de Comercio, Industria y Turismo (2016), en Colombia se presentan iniciativas de clústeres de turismo en algunos departamentos como Huila, Santader, Cauca y Tolima. Se tomó como referencia, la formulación del proyecto de clúster del departamento del Huila, el cual cuenta con cuatro lineas de accion cada una con actividades y pasos, que son: innovacion, desarrollo y comercialización de productos turísticos; especialización del talento humano; articulación entre los sectores público, privado y academia, y las tecnologías de la información y comunicaciones (Consejo Privado de Competitividad e Innpulsa Colombia, 2014). Con la declaratoria del PCCC, se busca el desarrollo del turismo cultural en el Quindío, mediante la integración productiva de los subsectores cultural y turístico, donde se aprovechen las ventajas comparativas y se generen ventajas competitivas que permitan potencializar las expresiones artísticas, culturales y patrimoniales, y promover un sello de autenticidad para el desarrollo socio económico del departamento.

El documento se estructura de la siguiente manera: primero se presenta la introducción, en segundo lugar se describe la metodología utilizada, en la tercera parte se incluyen los resultados, después las conclusiones y por último las referencias bibliográficas utilizadas en el desarrollo de la investigación que dio origen a este documento.

\section{Metodología}

Este estudio es de carácter cualitativo porque se identifican y explican las principales variables relacionadas con los subsectores cultural y turístico, además, porque no se refiere a variables aisladas del objeto de estudio sino 
a su totalidad, dentro de las cuales se destacan: situación actual de los mencionados subsectores y líneas de acción y actividades necesarias para la integración de los mismos. Es de carácter fáctico o empírico porque implica el uso de operaciones fundadas en la experiencia objetiva en la recolección y análisis de datos, y en el uso de conceptos y esquemas teóricos.

La presente es una investigación aplicada porque persigue fines de aplicación directa para resolver problemas prácticos en circunstancias y características concretas. Es exploratoria porque el objetivo es examinar un tema poco estudiado y que no ha sido abordado antes, sirve para obtener mayor información para desarrollar una investigación más completa, es flexible en su metodología y se interesa fundamentalmente en descubrir. Igualmente el estudio es descriptivo porque se tiene un conocimiento previo de la temática y se seleccionan unas variables a medir, las cuales permiten describir el fenómeno estudiado, y, aunque es posible que sean un poco rudimentarias, ofrece posibilidades para predecir el comportamiento del objeto de estudio.

La población analizada en el ámbito de la cultura corresponde a gestores y expertos del subsector; en la actividad turística corresponde a establecimientos como hoteles y restaurantes. Respecto al subsector cultural, la población estuvo conformada por las personas naturales y jurídicas inscritas en el registro de actores culturales de la Secretaría de Cultura de la Gobernación del Quindío, tales como grupos musicales, de danza, de teatro y de obras artísticas. Después de depurar la base de datos de actores culturales se logró que 30 actores culturales responndieran la encuesta oportunamente. Adicionalmente, se realizó una entrevista estructurada a expertos culturales del departamento, quienes asumen distintos roles en el gobierno local, la academia, los gremios y las empresas.

En cuanto al subsector turístico, se utilizó la base de datos de la Cámara de Comercio de Armenia y del Quindío, que registra los restaurantes y prestadores del servicio de alojamiento que actualizaron el Registro Mercantil a junio de 2012, con códigos CIIU H551 (hoteles) y CIIU H552 (restaurantes). Posteriormente, se depuró esta base de datos por el valor de los activos en cada uno de los registros, se inició con un valor de COL\$20 millones en activos (aproximadamente US\$5.208 a la TRM de octubre 9/2020). Se utilizó el muestreo a juicio del investigador, selección experta o selección intencional, que hace parte del método no probabilístico intencional, donde se toma la muestra a partir de los elementos que el investigador considera representativos o característicos de la población. Por lo anterior, este muestreo depende del criterio del investigador (Otzen y Manterola, 2017), y en este caso, el criterio es el valor de los activos como un factor que determina la estructura de la empresa con un potencial de demanda cultural para su oferta en turismo, con lo cual dió como resultado 116 establecimientos.

Para determinar la muestra de los establecimientos prestadores se servicios turísticos se utiliza la fórmula de muestreo tomando un 95\% de confiabilidad y un 4,3\% de margen de error (Ciro, 2016), con lo cual se obtiene una muestra de 95 establecimientos a encuestar. Con el muestreo estratificado para hoteles y restaurantes se obtiene que el $66,3 \%$ corresponde a los servicios de alojamiento que equivale a 63 establecimientos y el 33,7\% para restaurantes que corresponde a 32. Una vez conocido el número de empresas, se procedió a realizar muestreo aleatorio, generando el filtro para las empresas del subsector turístico que se debían encuestar.

Los instrumentos de recolección de la información fueron encuestas y entrevistas aplicadas a las fuentes primarias: gestores culturales y expertos y a prestadores de servicios turísticos. De otra parte, se consultaron fuentes secundarias como investigaciones sobre los subsectores cultural y turístico, estudios económicos, libros y documentos relacionados. 


\section{Resultados}

Este capítulo se encuentra dividido en tres subsecciones elaboradas con base en la información recolectada en el desarrollo de este estudio: inicialmente se presentan por separado la situación actual del subsector cultural y luego la del subsector turístico; posteriormente se esbozan las estrategias para la integración productiva de los subsectores cultural y turístico en el Quindío para el desarrollo del turismo cultural, con cuatro líneas de acción identificadas.

\subsection{Situación actual del subsector cultural}

La oferta cultural y artística, es decir, la creación cultural contemporánea en el departamento del Quindío se torna alrededor de las danzas y la música, las artes visuales y gráficas, la tradición oral y la literatura, la gastronomía, artesanías, ferias y fiestas, eventos y recorridos culturales. En el desarrollo del estudio, se identificaron las distintas manifestaciones donde no hay separación estricta entre lo tradicional y lo contemporáneo, además, en el contexto del PCCC se pueden agregar expresiones culturales artísticas y/o patrimoniales como los hallazgos arqueológicos, la arquitectura y la historia de los pueblos. A continuación, se relacionan las características del subsector cultural que posibilitan o limitan el desarrollo de procesos de articulación.

Se reconocen como fortalezas las siguientes:

- Amplia oferta con capacidad, creatividad, diversidad y dinamismo creciente en todos los campos del arte tales como agrupaciones artísticas representativas en el campo de la música, danzas y artes plásticas.

- En artesanías hay una importante representación cultural, trabajo y compromiso del artesano e iniciativas como la Aldea Quimbaya.

- En cuanto al patrimonio, hay indicios de una sociedad, reflejados en un alto acervo histórico y manifestaciones culturales existentes, pero poco a poco se han perdido porque no se muestran.

- Vanguardia cultural en la región, que permite generar una culturización a largo plazo.

- Reconocimientos económicos y en algunos casos simbólicos.

- Talento humano, espacios culturales, parques temáticos, casas de cultura, eventos, instituciones y grupos comprometidos.

De otra parte, se identifican las siguientes debilidades:

- Falta de apoyo gubernamental en presupuesto y logística y en acompañamiento en general.

- Situación financiera precaria por falta de recursos y liquidez, especialmente para la atención de requerimientos técnicos.

- Débil identificación y clasificación de la oferta, muchas actividades con pocos productos. Hay una sombrilla de subproductos.

- Falta de difusión, promoción y comercialización de los programas culturales, artísticos y patrimoniales reflejada en el desconocimiento de la oferta.

- Poca valoración de la identidad cultural (tradición y folclor) y débil reconocimiento del territorio.

- Precaria identidad en la diferenciación, que se ha convertido en una etiqueta usada por el turismo.

- $\quad$ Falta de iniciativa y formalización por parte de los gestores culturales.

- Desarticulación de los actores e intereses individuales por falta de conciencia y cooperación.

- Deficiente institucionalidad cultural, pese al reconocimiento, el subsector no es muy representativo.

- Falta de emprendimientos culturales y líneas de acción, lo que promueve la informalidad.

- Desarticulación del arte con la academia reflejado en falta de formación, investigación, creación y puesta en escena para el mejoramiento de la calidad. 
Como se puede notar, hay una variedad interesante y amplia de fortalezas y debilidades identificadas en el transcurso de la investigación.

\subsection{Situación actual del subsector turístico}

Respecto a los prestadores de servicios turísticos, hay una importante concentración de alojamientos en Armenia, por ser la ciudad capital, y Salento, por ser un destino turístico reconocido por tradición. Dentro de las principales características se encuentra que son alojamientos rurales en su mayoría, se subclasifican en alternativas como hotel campestre, finca hotel, finca tradicional y hostal, entre otras, lo cual es posible dadas las condiciones físicas y de biodiversidad del departamento que se convierten en un atractivo para los turistas al tener la posibilidad de interactuar con la naturaleza. Un importante porcentaje de alojamientos turísticos tienen una amplia capacidad, cuentan además con auditorios, salones u otros espacios y la logística necesaria para la realización de eventos, razón por la cual complementan su oferta con servicios como restaurante, transporte, visitas guiadas y bar, condiciones que les permite responder efectivamente a la demanda actual.

En cuanto a los restaurantes, al igual que los alojamientos, la mayor concentración está en Armenia y Salento, algunos de ellos se encuentran en las carreteras que interconectan los distintos municipios; la oferta se centra principalmente en la comida típica con lo cual se evidencia una importante apuesta de la región hacia lo autóctono; la mayoría de ellos tienen una amplia capacidad instalada y una logística adecuada para realizar eventos. Dentro de los servicios adicionales se destaca el bar y los juegos infantiles. Se presentan a continuación las características del subsector que posibilitan o limitan los procesos de articulación

Se reconocen las siguientes fortalezas:

- En lo ambiental: el paisaje, el clima, la biodiversidad

- En lo institucional: apoyo gubernamental con recursos económicos, presupuesto asignado y acompañamiento de otros entes no gubernamentales como el liderazgo del gremio cafetero y el buen nivel que tiene el departamento en seguridad ciudadana para los turistas; además, la buena infraestructura en servicios públicos y la conectividad interdepartamental.

- En lo cultural y patrimonial: la historia, cultura, gastronomía, arquitectura y embellecimiento de espacios y parques que generan movimiento económico y reconocimiento a nivel internacional, los múltiples escenarios establecidos y potenciales para el desarrollo del turismo cultural, además del capital humano y el espíritu amable de la gente.

- La declaratoria del PCCC para el turismo y la capacidad instalada crean una ventaja comparativa para el departamento del Quindío con un factor diferenciador en alojamiento, para generar una propuesta turístico-cultural.

Así mismo, se identifican las debilidades que a continuación se presentan:

- No existe una política de turismo cultural en el departamento del Quindío, sin embargo se dispone del Plan de Biocultura 2013-2023, el cual fue liderado desde la academia y contó con la participación de la ciudadanía.

- En lo económico, se reconoce la falta de planeación y por el contrario hay una visión muy comercial y cortoplacista que se limita únicamente al turismo rural, algunas veces se observa un turismo de aficionados e informal que no es profesional, razón por la cual se afirma que es desbordado y descontrolado. Así mismo, se evidencia poca competitividad, lo cual se refleja en la falta de mayor organización y generación de empleo, no se cuenta con personal bilingüe y además existen problemas de conectividad aérea y transporte especializado.

- En lo cultural, falta más educación del subsector turístico frente a la cultura y políticas que se deben integrar, además algunos manifiestan que es excluyente y egoísta. 
- En lo ambiental, no se mide el impacto ambiental a largo plazo, hay migración de nativos y llegada de extranjeros para apropiarse de la tierra.

- En lo institucional, organismos como La Asociación Colombiana de Agencias de Viajes y Turismo (ANATO), La Asociación Hotelera y Turística de Colombia (COTELCO) y la Cámara de Comercio de Armenia y del Quindío no establecen relaciones con el subsector cultural, falta de articulación con la educación, los gremios y los entes territoriales.

\subsection{Estrategias para la integración productiva de los subsectores cultural y turístico en el Quindío, para el desarrollo del turismo cultural}

Después de reconocer la situación actual de los subsectores cultural y turístico del departamento del Quindío, y con el propósito de articularlos para la integración productiva, se utilizó como referente las iniciativas de clúster de turismo lideradas por el Consejo Privado de Competitividad e Innpulsa Colombia, específicamente la propuesta realizada por el departamento del Huila, que define cuatro líneas de acción, las cuales fueron adaptadas a las características del Quindío. Por consiguiente, para iniciar un proceso de articulación, es indispensable un cambio de concepción frente a la construcción colectiva de futuro, el cual debe ser canalizado adecuadamente mediante una secuencia lógica de actividades que permitan direccionar los esfuerzos para el desarrollo del turismo cultural

\section{Línea de acción 1: Desarrollo e innovación de los subsectores}

Para la identificación de servicios complementarios que permitan atraer al turista y generar alianzas estratégicas orientadas al mejoramiento del servicio, se requiere:

1) En el análisis de la oferta turística y cultural

- Identificación de los gestores culturales del departamento que en realidad se encuentran en capacidad y disposición para integrar su oferta cutural, artística y patrimonial; esto se logra mediante la actualización de las bases de datos que maneja la Secretaría de Cultura Departamental, en donde estén debidamente clasificados por tipología, trayectoria y ubicación.

- Identificación y formación de lideres culturales que propendan por la recuperación y conservación de la identidad cultural y los valores artísticos y patrimoniales que definen y caracterizan al departamento, pero a su vez estimulen la promoción los mismos a través de una oferta clara y permanente que cumpla con criterios de calidad para su vinculación con el subsector turístico.

- Ampliación del espectro de prestadores de servicios turísticos (además de establecimientos de alojamiento y restaurantes) para la caracterización de la oferta turística y su interés en integrar dentro de su portafolio productos culturales, artísticos y patrimoniales

2) En el diseño y fortalecimiento de la imagen del departamento en torno a la oferta turística y cultural

- Establecimiento de una política que de viabilidad legal del turismo cultural en el departamento del Quindío, que se oriente a promoverlo e impulsarlo. Pese a que en la actualidad la Ley General de Turismo establece todos los lineamientos y orientaciones sobre los cuales municipios y departamentos desarrollan esta actividad económica, se requiere que en el departamento se dé atención especial a esta temática específica.

- Estructuración de un marco legal que regule el desarrollo de programas y proyectos de esta naturaleza y mecanismos efectivos de medición del alto impacto económico, social y cultural. Esto es posible mediante acuerdos (actos jurídicos de los concejos municipales) y/o ordenanzas (actos jurídicos de las asambleas departamentales) que garanticen su permanencia y sean reconocidos cuando haya cambios de gobierno.

3) En el diseño de rutas turísticas culturales 
- Integración de las distintas iniciativas generadas por los sectores y subsectores, como lo es la Red de Museos y las propuestas tanto por gestores culturales como operadores turísticos para la creación de rutas turísticas culturales que sean atractivas para los visitantes.

4) En la promoción de los productos culturales, artísticos y patrimoniales

- Fortalecimiento de las relaciones interinstitucionales donde gremios, operadores turísticos y medios de comunicación unifiquen criterios respecto a las estrategias de promoción y difusión de los productos generados en el turismo cultural.

- Estructuración de una agenda cultural mensual que sea promocionada desde distintos ámbitos reales y virtuales como aeropuertos, agencias de viajes, páginas web institucionales, restaurantes y establecimientos que prestan el servicio de alojamiento turístico.

- Vinculación de participación activa e incluyente de los distintos actores en eventos locales, regionales e internacionales como ferias y exposiciones.

5) En el desarrollo de programas para el mejoramiento de servicios turísticos y culturales de calidad.

- Planificación y organización de actividades culturales, artísticas y patrimoniales que reflejen las verdaderas tradiciones e idiosincrasia de la región, en donde se asignen tiempos de ejecución, responsables, recursos y logística requerida para tal fin.

\section{Línea de acción 2: Especialización del talento humano}

Para el desarrollo de competencias del talento humano del departamento del Quindío, es necesario:

1) En la identificación de contenidos apropiados para la sensibilización del turismo cultural a infantes y juveniles

- Estructuración de programas de capacitación a operadores turísticos y comunidad en general sobre cultura en el departamento y realización de talleres para el diseño de productos turísticos culturales más atractivos.

- Formación en artes y cultura a niños y adolescentes para el estímulo a la creatividad e innovación, así como educación sobre la cultura cafetera, las costumbres, valores e idiosincrasia, que permitan el fortalecimiento de la identidad cultural

2) En el fortalecimiento y desarrollo de competencias en bilinguismo

- Desarrollo de programas de capacitación en segunda lengua para operadores turísticos y comunidad en general; las universidades del departemento ofrecen programas de educación no formal, como diplomados y cursos cortos en ingles.

- Planificación y fortalecimiento de programas de formación en segunda lengua para niños y adolescentes desde la educación básica primaria hasta la educación superior.

3) En la participación en semilleros de investigación tur

4) En la realización de alianzas entre instituciones gremiales y educativas para la formación de empresarios y participantes.

- Estimulo a los procesos de asociatividad de gestores culturales de acuerdo con la naturaleza de su oferta y verificar el papel que están jugando las actuales asociaciones y el liderazgo ejercido por las mismas para el crecimiento y desarrollo del subsector.

\section{Línea de acción 3: Incorporación de los actores de los subsectores turístico y cultural del departamento}

a) En el diseño de planes para mejorar las relaciones entre los actores del turismo cultural. Para desarrollarse adecuadamente, es necesario:

- Generar espacios de sensibilización respecto a la importancia de articular ambos subsectores para el crecimiento y desarrollo del departamento 
- Iniciar esfuerzos para la construcción de relaciones de confianza, en donde se generen acuerdos y compromisos y se establezcan mecanismos de seguimiento y control a los mismo

b) En la creación de mesas de participaciones de los actores en los que expongan sus puntos de vista y necesidades (intervención activa del sector público, privado y la academia)

- Fundamentado en una política de turismo cultural en el departamento del Quindío, se requiere la creación de un comité que incorpore a representantes de los subsectores turístico y cultural, entes gubernamentales, agremiaciones y academia para discutir las necesidades y visión de futuro y se unifiquen criterios respecto a la ruta de trabajo como resultado de un proceso de construcción colectiva.

c) En la articulación de las necesidades del departamento y las de los diferentes participantes para promover el desarrollo turístico cultural.

- Análisis de la relación costo beneficio que representa para ambos subsectores la integración productiva, partiendo de la identificación de necesidades, así como las ventajas comparativas y la estrategia para la generación de ventajas competitivas.

d) En la vinculación de la ciudadanía para que participe en campañas de promoción.

- Desarrollo de actividades continuas de sensibilización y capacitación a la comunidad para el reconocimiento del portafolio de productos de turismo cultural y la promoción de los mismos.

\section{Línea de acción 4. Utilización de las tecnologías de la información y comunicación (TICs)}

Para lograr mayor visibilidad a nivel regional, nacional e internacional, se deben aprovechar las tecnologías de la información y la comunicación, para lo cual es necesario:

a) En el establecimiento de una página oficial que identifique la oferta turística del Quindío con los componentes culturales, artísticos y patrimoniales

- Generar interacción virtual con los entes gubernamentales, agremiaciones, operadores turísticos y gestores culturales entre otros para integrar la oferta y estructurar paquetes que respondan a las necesidades y expectativas de los turistas.

- Creación de redes virtuales a través de las cuales el turista pueda seleccionar rutas

b) Creación de un directorio turístico cultural virtual

- Incluir el inventario de productos turísticos culturales con sus principales características y se apoye en imágenes y videos con los cuales turistas nacionales e internacionales se sientan más atraídos a visitar el departamento.

Como se puede observar, es necesario un cambio de concepción, de manera que sea posible iniciar un proceso de construcción colectiva de futuro, donde se reconozca el potencial del turismo cultural en el Quindío, razón por la cual, las estrategias propuestas para la integración productiva de los subsectores, deben ser impulsadas desde distintos estamentos de manera que sea posible generar ventas competitivas y esta importante alternativa se convierta en un factor de desarrollo socioeconómico para el departamento.

\section{Conclusiones}

Dentro de las principales fortalezas del subsector se encuentra una amplia oferta en música, danza, artes plásticas y artesanías, entre otras, las cuales cuentan con una importante representación; igualmente se destaca la parte humana, los espacios culturales, parques temáticos, casas de cultura, eventos, instituciones y grupos comprometidos. No obstante, son más las debilidades identificadas tales como la falta de apoyo gubernamental, la situación financiera precaria, débil clasificación de la oferta, falta de promoción y comercialización, carencia de identidad cultural, falta de iniciativa y formalización, desarticulación de los actores e intereses individuales, 
falta de emprendimientos culturales y distanciamiento del arte con la academia, reflejado en falta de formación e investigación, así como la creación y puesta en escena para mejorar la calidad.

En lo relacionado con el subsector turístico, las principales características son: el paisaje, clima y biodiversidad; apoyo gubernamental, presupuesto y recursos, liderazgo del gremio cafetero, adecuada infraestructura de servicios públicos, conectividad interdepartamental, además del potencial que representan el capital humano, las costumbres e idiosincrasia de la región. Como debilidades se reconoce la inexistencia de una política de turismo cultural, la falta de planeación y visión comercial y cortoplacista limitada únicamente al turismo rural, falta de organización y generación de empleo, personal poco capacitado en bilingüismo, en cultura y en competencias asociadas a esta actividad económica, problemas de conectividad aérea y transporte especializado, falta de medición del impacto ambiental, desarticulación con la educación, gremios y entres territoriales.

Para iniciar un proceso de articulación entre los dos subsectores se requiere como punto de partida un cambio de concepción frente a la oferta cultural, artística y patrimonial tanto de gestores culturales como de operadores turísticos, quienes en la actualidad tienen posturas totalmente opuestas, y pese a que ambos tienen razón en cierta medida, se requiere unificar criterios respecto al significado del turismo cultural y su importancia para el crecimiento y desarrollo del departamento del Quindío. Así mismo se hace necesario sensibilizar a los distintos actores respecto al inmenso potencial que tiene esta iniciativa y generar voluntad política y de los líderes empresariales y gremiales para construir relaciones de confianza.

Dentro de las estrategias generadas para el desarrollo e innovación de los subsectores se encuentra el análisis de la oferta turística y cultural, el diseño y fortalecimiento de la imagen del departamento en torno a la oferta turística y cultural, el diseño de rutas turísticas culturales, la promoción de los productos culturales, artísticos y patrimoniales y el desarrollo de programas para el mejoramiento de servicios turísticos y culturales de calidad. En cuanto a la especialización del talento humano, se proponen estrategias relacionadas con la identificación de contenidos apropiados para la sensibilización del turismo cultural a infantes y juveniles, el fortalecimiento y desarrollo de competencias en bilinguismo, la participación en semilleros de investigación turística y la realización de alianzas entre instituciones gremiales y educativas para la formación de empresarios y participantes.

Parta la incorporación de los actores de los subsectores turístico y cultural del departamento, se requiere de estrategias relacionadas con el diseño de planes para mejorar las relaciones entre los actores del turismo cultural, la creación de mesas de participaciones de los actores en los que expongan sus puntos de vista y necesidades, donde es vital la intervención activa del sector público, privado y la academia, la articulación de las necesidades del departamento y las de los diferentes participantes para promover el desarrollo turístico cultural y la vinculación de la ciudadanía para que participe en campañas de promoción. Por último, en lo relacionado con la utilización de las tecnologías de la información y comunicación (TICs), en el establecimiento de una página oficial que identifique la oferta turística del Quindío con los componentes culturales, artísticos y patrimoniales, y la creación de un directorio turístico cultural virtual

\section{Referencias bibliográficas}

Campodónico, G. 2014. Relaciones entre cultura, turismo y patrimonio: apuntes desde la investigación sociocultural en Uruguay. En A. Falero, y R. Campodónico, El turismo bajo la lupa acádemica (p.p. 41-54). Montevideo: Ediciones Universitarias. Recuperado de: https://www.colibri.udelar.edu.uy/jspui/bitstream/20.500.12008/4521/1/FHCE-falero_pdf.pdf 
Aldamiz, C., Aguirre, M. S. y Aparicio, M. G. (2014). Orígenes, elementos determinantes y resultados de un exitoso proceso de colaboración entre competidores y otros agentes: el cluster de la Alta Cocina Vasca. Cuadernos de Gestión, 4(2), 51-72. Recuperado de: http://www.ehu.eus/cuadernosdegestion/documentos/120385ca.pdf

Anato, M., Rivas, B. y González, M. (2010) Paisaje e identidad cultural en la promoción de la imagen de Isla margarita como destino turístico. Revista de Turismo y Patrimonio Cultural-PASOS, (8)1, 113-124. Recuperado de: https://www.redalyc.org/pdf/881/88112836009.pdf

Ciro, B. (2016). Estadística básica aplicada. Ed. 4ạa, Bogotá: Ecoe Ediciones.

Confortí, M. E., González, N., y Endere, M. (2014). El desafío de articular turismo cultural y patrimonio arqueológico - El caso de Olavarría, Argentina. Estudios y Perspectivas en Turismo, 23, 749-767. Recuperado de: https://www.redalyc.org/pdf/1807/180732145006.pdf

Consejo Nacional de Política Económica y Social, CONPES. (2014). Política para la preservación del Paisaje Cultural Cafetero de Colombia. (Documento 3803). Bogotá, Colombia. Recuperado de: https://colaboracion.dnp.gov.co/CDT/Conpes/Econ\%C3\%B3micos/3803.pdf

Consejo Privado de Competitividad - Innpulsa Colombia. (2014). Documento líneas de acción del Clúster de Turismo - Huila Clúster Turismo. Competitiveness. Red Cluster Colombia. Recuperado de: https://www.redclustercolombia.com/assets/recursos/iniciativas/pdfs/Ruta-de-turismo_1.pdf

Corona, E., Zárraga, L. y Ruiz, J. (2015). Innovación en el sector turístico de Cancún- Evidencias Empíricas. Revista Internacional Administración \& Finanzas, 8(4), 93-105. Recuperado de: http://www.theibfr2.com/RePEc/ibf/riafin/riaf-v8n4-2015/RIAF-V8N4-2015-6.pdf

Departamento Nacional de Planeación. (2007). Agenda Interna para la Productividad y Competitividad. Documento Regional Quindío. Bogotá, Colombia. Recuperado de: http://cpps.dyndns.info/cpps-docsweb/planaccion/biblioteca/pordinario/Colombia/documentos\%20DNP/Agenda\%20Interna\%20para\%20la \%20Productividad\%20y\%20competitividad\%20Cesar.pdf

Duis, U. (2007). La valorización cultural, social y turística de los recursos culturales y naturales como instrumento para la planificación turística, la conservación del Paisaje Cultural Cafetero y el desarrollo sostenible del territorio turístico. Turismo y sociedad, 8, 69-79. Recuperado de: https://revistas.uexternado.edu.co/index.php/tursoc/article/view/2170

Duis, U. (2011). Caminos e historias de la tierra cafetera: la unión entre territorio, paisaje cultural y su gente como producto experiencial del turismo cultural. Anuario Turismo y Sociedad, 12, 83-109. Recuperado de: https://revistas.uexternado.edu.co/index.php/tursoc/article/view/3118

García, L. (2004). El desarrollo local como estrategia de desarrollo emergente. Revista de Historia: Presente y pasado, 8(17), 137-152. Recuperado de: http://www.saber.ula.ve/bitstream/handle/123456789/22981/articulo8.pdf;jsessionid=9AB67607EE7226 4C7547BFE3FC7FC07C?sequence $=2$

García, M. L. y Vargas, L. C. (2016). Visión estratégica del turismo en el Paisaje Cultural Cafetero. Armenia: Universidad La Gran Colombia. Recuperado de: https://www.ugc.edu.co/sede/armenia/files/editorial/vision_estrategica_de_turismo_pcc.pdf 
Guzmán, L. y García, G. (2010). Fundamentos teóricos para una gestión turística del patrimonio cultural desde la perspectiva de la autenticidad: Recuperado de:

http://biblioteca.utec.edu.sv/siab/virtual/elibros_internet/55744.pdf

Guzmán, L. (2013). El patrimonio cultural de Holguin: Gestión turística desde la perspectiva de la autenticidad. (Tesis doctoral). Granada, Universidad de Granada. Recuperado de: https://hera.ugr.es/tesisugr/22210106.pdf

Guzmán, B., Parra, R. y Tarapuez, E. (2019). Identidad y manifestacionesa culturales del departamento del Quindío en el contexto del Paisaje Cultural Cafetero de Colombia. Cuadernos de Turismo, 44, 165-192. Recuperado de: https://revistas.um.es/turismo/article/view/404801/274871

Ministerio de Comercio, Industria y Turismo e Innpulsa Colombia. (2016). Clústeres. Recuperado de: https://www.mincit.gov.co/minindustria/estrategia-sectorial/clusteres

Ministerio de Cultura (2007). Política de Turismo Cultural. Bogotá. Recuperado de: https://www.mincultura.gov.co/SiteAssets/documentos/Turismo/Politica.pdf

Myttenaere, B. y Rozo, E. (2010). Desarrollo Territorial y Turismo: Una aproximación a partir de la valorización turística. Bogotá: Universidad Externado de Colombia.

Otzen, T., \& Manterola, C. (2017). Técnicas de Muestreo sobre una Población a Estudio. International Journal of Morphology, Vol. 35 (1), 227-232. Recuperado de: www.sitios.ingenieriausac.edu.gt/estadistica/estadistica

Porter, M. (1998). Clusters and the new economics of competition. Harvard Business Review, p. 77 - 90. Recuperado de: https://hbr.org/1998/11/clusters-and-the-new-economics-of-competition

Rius J. y Zarlenga M., (2014). Industrias, distritos, instituciones y escenas: Tipologías de clústeres culturales en Barcelona. RES. 21, 47-68. Recuperado de:

https://www.researchgate.net/publication/274456344_Industrias_distritos_instituciones_y_escenas_Tipo logia_de_clusteres_culturales_de_Barcelona/link/552011f00cf2a2d9e14334c5/download

Sanabria, T. (2010). Consolidación de estructuras turístico - culturales - en la construcción del desarrollo territorial a escala humana. Universidad Nacional de Colombia. Bitácora 17(2), 127-144. Recuperado de: https://www.researchgate.net/publication/50407252_Consolidacion_de_estructuras_turisticoculturales_En_la_construccion_del_desarrollo_territorial_a_escala_humana_Consolidation_of_TouristicCultural_Structures_In_the_Construction_of_the_Territorial_De

Troitiño, M. (2002). Elementos y técnicas de análisis territorial, Documento electrónico. Recuperado de: https://es.scribd.com/document/122840583/Elementos-y-Tecnicas-Del-Analisis-Territorial

Varisco, C. (2007). Iniciativas de desarrollo local y fomento del clúster turístico. Aportes y Transferencias, 11(1), 31-42. Recuperado de: https://www.redalyc.org/pdf/276/27611103.pdf

Esta obra está bajo una Licencia Creative Commons Attribución-NoCommercial 4.0 International

(cc) BY-NC 